\title{
Use of the partogram in labor: Analysis of its application in different care models
}

\author{
Cláudia de Azevedo Aguiar $^{1 *}$, Roselane Gonçalves ${ }^{2}$, Ana Cristina d’Andretta Tanaka ${ }^{3}$ \\ ${ }^{1}$ Faculdade de Saúde Pública, Universidade de São Paulo, São Paulo, Brazil \\ ${ }^{2}$ Escola de Artes, Ciências e Humanidades, Universidade de São Paulo, São Paulo, Brazil \\ ${ }^{3}$ Department of Maternal and Child Health, Faculdade de Saúde Pública, Universidade de São Paulo, São Paulo, Brazil \\ Email: ${ }^{*}$ claudia.azevedo@usp.br, roselane@usp.br, acdatana@usp.br
}

Received 17 September 2013; revised 14 October 2013; accepted 20 October 2013

Copyright (C) 2013 Cláudia de Azevedo Aguiar et al. This is an open access article distributed under the Creative Commons Attribution License, which permits unrestricted use, distribution, and reproduction in any medium, provided the original work is properly cited.

\begin{abstract}
Objective: To compare and identify possible differences in the use of the partogram in different models of delivery and birth care. Design/Setting: This was a cross-sectional study performed in two Brazilian hospitals with different models of care: Natural Birth Center (NBC) and Traditional Obstetric Center (TOC). Data were collected from the medical records of $\mathbf{1 1 2}$ mothers with low obstetric risk who underwent an intrapartum cesarean section. Socioeconomic and demographic variables, obstetric history, partogram labor evolution, complications, and indication of cesarean section were included. A significance level of $5 \%$ and a confidence interval of $95 \%$ were considered. Data were analyzed in accordance with the Brazilian Ministry of Health and World Health Organization recommendations. Findings: In the NBC, the use of the partogram follows the Ministry of Health recommendations for filling-in variables with greater frequency and significance $(p<0.001)$ beginning with the active phase of labor in the correct column in relation to the lines of alert and action $(p=0.00, \mathrm{OR}=$ 42.2) and continuous records $(p=0.00, O R=53.3)$. However, obstetric interventions, such as use of oxytocin, amniotomy and cesarean delivery were concentrated in area 1 of the partogram in both institutions. Conclusions: In this study, the NBC used the instrument most adequately; however there was no difference from the other model (TOC) and regarding the moment of interventions, many of them were early. This finding implies that, regardless of the care model, the partogram has been used bureaucratically and not as a guiding instrument of assistance envisioning safely and timely practices. In other words,
\end{abstract}

\footnotetext{
Corresponding author.
}

aside from a "humanized" physical structure, it is necessary that obstetric practices should be focused on best evidence, thus reducing maternal and perinatal risks.

Keywords: Partogram; Childbirth Care; Birth Center; Obstetrical Surgical Center

\section{INTRODUCTION}

The partogram is a tool to register maternal and fetal conditions; it also enables a quick visualization of labor progress.

In 1965, Philpott developed this instrument, based on Friedman improvements in cervicography [1]. In 1972, Philpott and Castle tested the partogram in a study performed in Rhodesia (Africa). For this study, they draw lines of "action" and "alert" in the partogram to detect potential risk labors of women who needed to be transferred from the countryside to a specialized medical center $[2,3]$.

During the 1970's, research reaffirmed the effectiveness of the partogram for reducing long labors, caesarian sections and perinatal death during deliveries [1].

In the early 1990's, the World Health Organization (WHO) conducted a multicentric study about this instrument with more than 35 thousand women, including both nullipara and multipara, which showed a reduction of $3 \%$ in prolonged deliveries, $11 \%$ in interventions to increase delivery rhythm, $1.6 \%$ in caesarian sections, and $0.2 \%$ in stillborn children. As a consequence of these results, considering the use of the partogram as a safe and effective practice, the Organization began to recommend its use as an essential instrument to promote and control maternal and perinatal health $[1,4]$.

The Partogram as recommended by WHO and adopted 
by the Brazilian Ministry of Health (BMH), contemplates three main labor components: fetal conditions, maternal conditions and the progress of labor. Fetal conditions consider cardiac frequency of the fetus and amniotic liquid aspect. Maternal conditions refer to vital signs, urine, bleeding, maternal position, and several intercurrence events. The progress of labor relates to the dilation of cervix, fetal presentation, and conditions of uterine contractions (frequency, intensity and duration) [1,5].

The partogram, since its idealization and prescription, has been a target of discussion. An argument, sometimes used against the partogram, is that it restricts clinical practice, since the registration of its measures presupposes the evolution of labor, based on an ideal preconceived time for the active phase of delivery care $(1 \mathrm{~cm}$ per hour).

Systematic reviews demonstrated that routine use of the partogram, for obstetric care, has no effect on reducing intrapartum interventions (use of oxytocin, amniotomy, for example) [6,7]. Nevertheless, Brazilian studies $[8,9]$ point to positive effects of this instrument in maternal and perinatal results, ratifying WHO recommendations of the partogram use for almost two decades $[4,10]$.

In accordance with the WHO [4] and the Brazilian Ministry of Health [5], the proposed partogram model is valid and recommended for any models of care during childbirth.

In Brazil, the two main scenarios of delivery and birth care are the traditional Obstetric Centers and the Natural Birth Centers. An obstetrician, a midwife or an obstetric nurse provide the obstetric assistance in these two models. In the case of the City of São Paulo, where the attendance is provided by the Brazilian National Healthcare System (SUS), nurses or midwives give obstetric assistance in labors considered of low or average risk.

Obstetric Centers are connected to surgery centers of hospitals. Natural birth, instrumental vaginal deliveries, caesarian sections, and curettages are performed there. These centers are separated from antepartum and postpartum rooms, which, in turn, are normally collective. As for being traditional, the Obstetric Centers dispose of an obstetric table for surgery and, in this context; interventions and practices tend to be more invasive. On the other hand, Natural Birth Centers were regulated in 1999, aiming to provide humanized assistance with quality to natural births without dystocia. These centers dispose of a unique layout with unified antepartum, labor and postpartum rooms. Those using the NBC find practice based on better evidences, promotion of privacy and freedom for women and their companions.

Despite the Brazilian Health Ministry recommendation for a humanized and safe assistance during labor and birth, obstetric interventions are really high in the country and the caesarian section index during the last year were higher than the natural delivery births $(52.3 \%$ of total caesarian sections, of which $90 \%$ were in private hospitals and 35\% in SUS).

Accordingly, the hereby study intended to compare the use of the partogram before caesarian section in two different scenarios of care during labor and childbirth: traditional Obstetric Center and Natural Birth Center. Therefore, the intention was to verify if the Natural Birth Centers, created in Brazil to oppose the traditional model of the Obstetric Centers in order to humanize the assistance through practices based on evidences, such as the use of partogram, is safe for mother and child. The "Intrapartum caesarian delivery" event is considered as a great indicative of quality in care during childbirth, and the partogram is a proper tool to register clinical care practices and maternal-fetal findings.

\section{METHODS}

This was a cross-sectional study performed in two hospitals located in the City of São Paulo, Brazil. Every mother of low obstetric risk was included, they underwent intrapartum caesarian sections in the year of 2010 and their deliveries were registered in the Partogram. Women with gestational age $\geq 37$ weeks, with only one and an alive fetus in cephalic presentation, with normal clinical and obstetric examination and who were admitted in the hospital diagnosed as in labor were considered low risk. All data were registered in these women's hospital records.

In one of the hospitals, low-risk pregnant women were assisted in intra-hospital Natural Birth Center, whereas in the other hospital, the assistance is performed in the traditional Obstetric Center. The herein referred hospitals are denominated NBC (Hospital with Natural Birth Center) and TOC (Hospital with Traditional Obstetric Center) and their characteristics are described in Chart 1.

It is important to state that NBC is a maternal-hospital of reference for high-risk pregnancy throughout the City of São Paulo; accordingly, this is the reason why many women are not admitted to NBC when presenting highrisk conditions.

There were a total of 23 puerperal women in NBC and 89 in TOC.

Secondary data were collected in records of puerperal women, including socioeconomic information, obstetric information, hospitalization data, and labor progress registered in the partogram, as well as information about caesarian indication.

Both institutions studied have adopted the partogram recommended by the Brazilian Ministry of Health [5] (Figure 1) for delivery care (model with lines of alert and action already determined with intervals of 4 hours between the lines). 
Chart 1. Characterization of places of study.

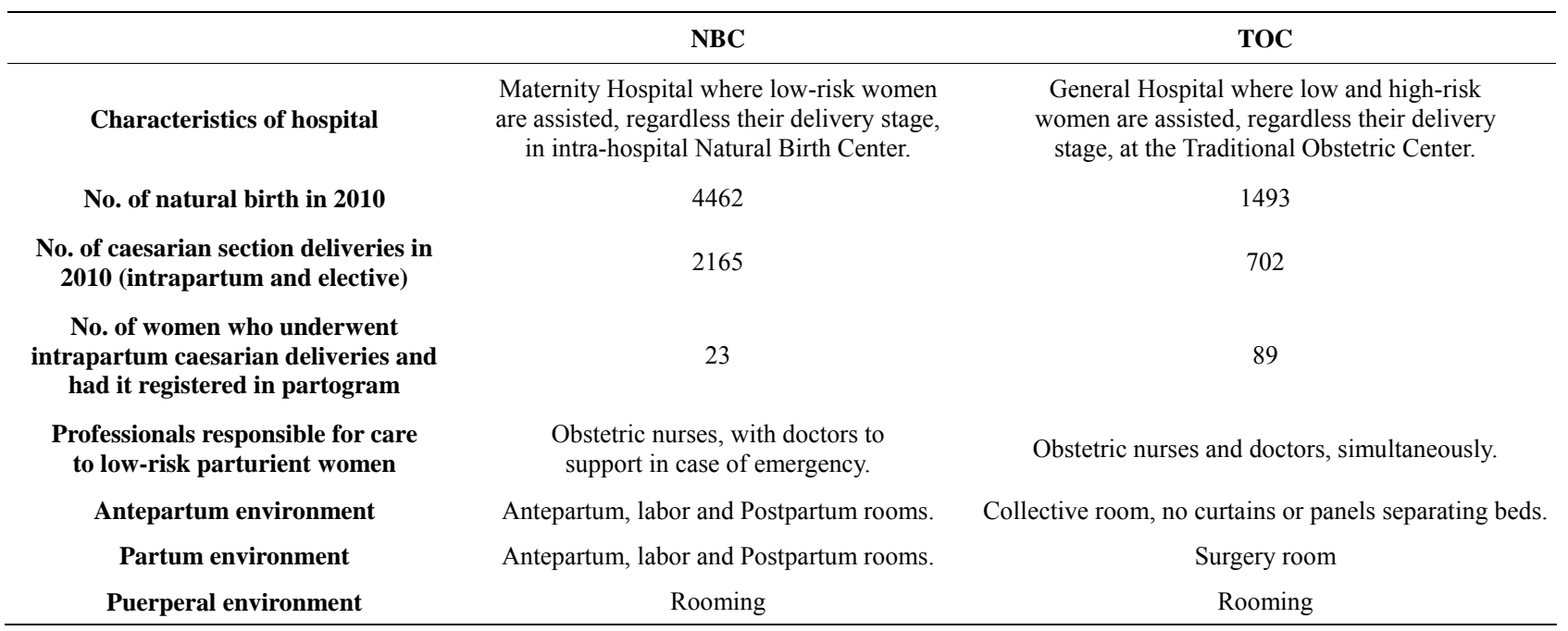

According to Brazilian Ministry of Health regulations for a correct use of the partogram, it must be fulfilled as follows:

1) The registration on the chart is started when the parturient is really in the active phase of the labor (two to three efficient contractions every 10 minutes and minimal cervix dilation of $3-4 \mathrm{~cm}$ );

2) Line of alert must be traced in the following hour to the first registration of cervix dilation. Line of action must be traced in parallel after 4 hours.

3) Subsequent vaginal examinations should be taken every two hours, however each column of the chart must correspond to 1 hour.

For data analysis, the following variables were studied: the partogram starting moment in relation to the phase of labor, start of fulfilling the partogram in relation to line of alert (correct column), continuous registration (1 hour per column), registration of maternal and fetal findings and registration of interventions.

Data were processed in Stata ${ }^{\circledR}$, version 11.0, taking into consideration the significance level of 5\% $(p<0.05)$ and Confidence interval (CI) of 95\%. For statistical analysis, test $\chi^{2}$ Mantel-Haenszel was used; and the Fischer exact test was adopted for intervals lower than five. Odds Ratio (OR) was calculated to estimate risk.

The results were described in the attached tables.

This study respected ethical aspects of the Brazilian regulation regarding research involving human beings (Regulation nr. 196/96), and the Research Ethical Committees approved the institutions involved (Protocols 2218; 0010.0.207.162-11; e 004/11).

\section{RESULTS}

Twenty-three (23) women of NBC and eighty-nine (89) of TOC had, respectively, the following characteristics: between 14 and 40 years of age; $61.4 \%$ and $63.6 \%$ were housewives; $50 \%$ and $37.9 \%$ had white complexion. In regard to education, despite the amount of reports without this information, $38.5 \%$ of the women at NBC declared to have concluded High School, against 28\% at TOC.

In respect to obstetric history, parturient women were between 37 and 42 weeks of pregnancy, in that most of them were primigravidae $(69.2 \%$ at $\mathrm{NBC}$ and $55 \%$ at TCO).

In reference to filling-in variables of the partogram, the device started, in $100 \%$ of the NBC cases, when women were in the active phase of labor, whereas in TOC, $76.4 \%$ of the in-labor women were not in the active phase of labor (Table 1).

Additionally for the beginning of the partogram registration, $89.9 \%$ of NBC cases against $17.4 \%$ of TCO cases occurred in an incorrect column in relation to line of alert. This data was statistically significant $(p=0.000 / \mathrm{OR}=$ $42.2 / \mathrm{IC}=10.3-191.5)$ when both institutions were compared (Table 1).

A discontinuation in registration was observed in $71.8 \%$ of the cases at TOC and, therefore, this result was statistically significant $(p=0.000 / \mathrm{OR}=53.3 / \mathrm{IC}=7$ 1117) (Table 1).

In relation to clinical findings and interventions, the fetal heart beat (FHB), uterine contraction patterns, water-bag integrity, and amniotic liquid aspects were registered in $100 \%$ of the NBC cases. Such registrations were present for most of the population studied in the TOC. However, despite its statistical significance $(p=0.004 /$ $\mathrm{OR}=9.2 / \mathrm{IC}=1.3-78.7)$, both institutions had few registrations about variation in positioning $(17.4 \%$ at $\mathrm{NBC}$ and $2.2 \%$ at TOC) (Table 1).

Registration of non-pharmacological methods for pain relief was statistically significant when both institutions 


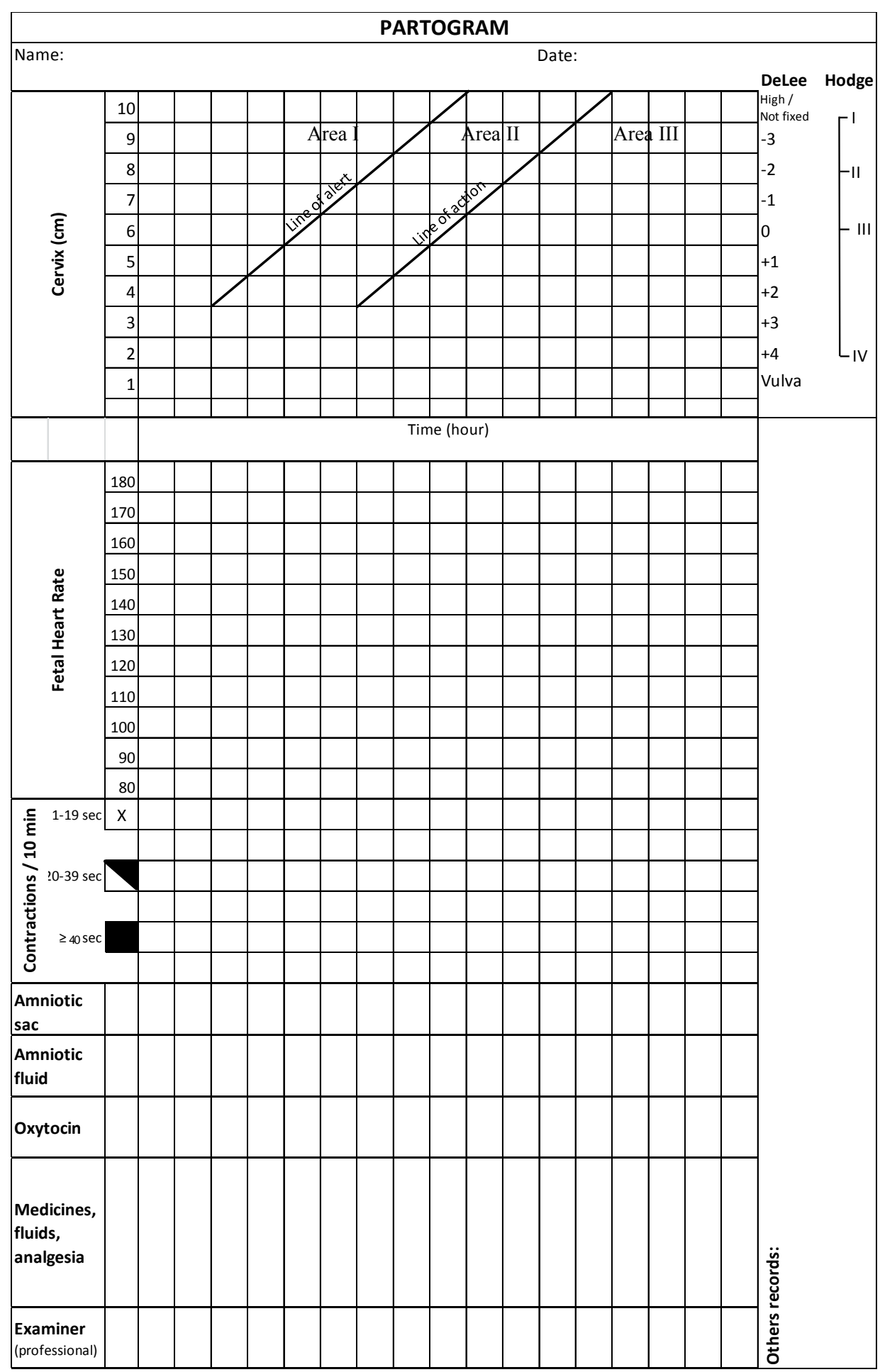

Figure 1. Model of partogram recommended by the Brazilian Ministry of Health [5].

are compared $(p=0.000 / \mathrm{OR}=93.2 / \mathrm{IC}=11.8-1987)$, which demonstrated that a better result was achieved at NBC (Table 1).

Another relevant data with statistical significance $(p=$ $0.000 / \mathrm{OR}=300 / \mathrm{IC}=20.1-11451)$ was the use and control of oxytocin infusion. Fifty-two (52) women at TOC underwent the use of this drug, and only $02(3.8 \%)$ of them had this fact registered in the partogram (Table 1).

With reference to the moment of obstetric interventions, they occurred, primarily, in area I of the partogram (before line of alert), either at TOC or NBC (Tables 2 and 3). 
Table 1. Frequency, value of $p, \operatorname{Odds}$ Ratio $(\mathrm{OR})$ and confidence interval $(\mathrm{CI})$ in regard to filling-in the partogram variables by health institutions. São Paulo, Brazil (2010).

\begin{tabular}{|c|c|c|c|c|c|c|c|}
\hline \multirow{3}{*}{$\begin{array}{l}\text { Filling-in partogram variables } \\
\text { (Brazilian Ministry of Health model) }\end{array}$} & \multicolumn{2}{|c|}{ NBC } & \multicolumn{2}{|c|}{ TOC } & \multirow{3}{*}{ Value of $p$} & \multirow{3}{*}{ OR } & \multirow{3}{*}{ CI } \\
\hline & Yes & No & Yes & No & & & \\
\hline & $\mathbf{N}(\%)$ & N (\%) & $\mathbf{N}(\%)$ & N (\%) & & & \\
\hline Beginning of the partogram in active phase & $23(100 \%)$ & - & $21(23.6 \%)$ & $68(76.4 \%)$ & * & * & * \\
\hline Opening in correct column in relation to line of alert & $19(82.6 \%)$ & $4(17.4 \%)$ & $9(10.1 \%)$ & $80(89.9 \%)$ & 0.000 & 42.2 & $10.3-191.5$ \\
\hline Continued registration (1 hour per column) & $22(95.6 \%)$ & $1(4.4 \%)$ & $26(29.2 \%)$ & $63(71.8 \%)$ & 0.000 & 53.3 & $7-1117$ \\
\hline \multicolumn{8}{|l|}{ Registrations of findings and interventions: } \\
\hline Cervix dilation $^{\mathbf{A}}(\mathrm{cm})$ & $22(95.6 \%)$ & $1(4.4 \%)$ & $63(71.8 \%)$ & $26(29.2 \%)$ & 0.013 & 9.1 & $1.2-190.0$ \\
\hline Descent of presentation $^{\mathbf{A}}$ & $22(95.6 \%)$ & $1(4.4 \%)$ & $63(71.8 \%)$ & $26(29.2 \%)$ & 0.013 & 9.1 & $1.2-190.0$ \\
\hline Variation of positioning & $4(17.4 \%)$ & $19(82.6 \%)$ & $2(2.2 \%)$ & $87(97.8 \%)$ & 0.004 & 9.2 & $1.3-78.7$ \\
\hline $\mathrm{FHB}^{\mathrm{B}}$ & $23(100 \%)$ & - & $87(97.8 \%)$ & $2(2.2 \%)$ & * & * & * \\
\hline Uterine contraction patterns ${ }^{\mathrm{C}}$ & $23(100 \%)$ & - & $73(82.0 \%)$ & $16(18.0 \%)$ & * & $*$ & * \\
\hline Integrity of water-bags & $23(100 \%)$ & - & $88(98.9 \%)$ & $1(1.1 \%)$ & ${ }^{*}$ & * & $*$ \\
\hline Aspect of amniotic liquid & $23(100 \%)$ & - & $84(94.4 \%)$ & $5(5.6 \%)$ & $*$ & * & $*$ \\
\hline Oxytocin (drip method/quantity) ${ }^{\mathbf{D}}$ & $12(92.3 \%)$ & $1(7.7 \%)$ & $2(3.8 \%)$ & $50(96.2 \%)$ & 0.000 & 300 & $20.1-11451$ \\
\hline Non-pharmacological methods & $22(95.6 \%)$ & $1(4.4 \%)$ & $17(19.1 \%)$ & $72(80.9 \%)$ & 0.000 & 93.2 & $11.8-1987$ \\
\hline
\end{tabular}

${ }^{\mathrm{A}}$ Every 2 hours, at least; ${ }^{\mathbf{B}}$ Every hour, at least; ${ }^{\mathbf{C}}$ Quantity and duration, at least, before and during oxytocin infusion and during registration of cervix dilation and descent of fetal presentation; ${ }^{D}$ Referred to women who received oxytocin (NBC N $=13 / \mathrm{TOC} N=73$ ); ${ }^{*}$ Value of $p$, CI and OR not defined for not having been observed during one of the events.

Table 2. Initial use of obstetric interventions, in relation to Partogram Area in Tradicional Obstetric Center (HOC). São Paulo, Brazil (2010).

\begin{tabular}{|c|c|c|c|c|c|c|c|c|}
\hline \multirow{3}{*}{ TOC interventions } & \multicolumn{6}{|c|}{ Partogram areas } & \multirow{2}{*}{\multicolumn{2}{|c|}{$\begin{array}{l}\text { Total of women who } \\
\text { underwent the procedure }\end{array}$}} \\
\hline & \multicolumn{2}{|c|}{$\mathbf{I}$} & \multicolumn{2}{|c|}{ II } & \multicolumn{2}{|c|}{ III } & & \\
\hline & $\mathbf{N}$ & $\%$ & $\mathbf{N}$ & $\%$ & $\mathbf{N}$ & $\%$ & $\mathbf{N}$ & $\%{ }^{*}$ \\
\hline Use of oxytocin & 52 & 100.0 & 00 & 0.0 & 0 & 0.0 & 52 & 58.4 \\
\hline Use of amniotomy & 38 & 95.0 & 02 & 5.0 & 0 & 0.0 & 40 & 44.9 \\
\hline Use of non-pharmacological methods & 21 & 95.5 & 01 & 4.5 & 0 & 0.0 & 22 & 24.7 \\
\hline Caesarian delivery indication & 79 & 88.8 & 10 & 11.2 & 0 & 0.0 & 89 & 100.0 \\
\hline
\end{tabular}

*Percentage in relation to the total number of women $(n=89)$.

Table 3. Initial use of obstetric interventions, in relation to Partogram Area in Natural Birth Center (NBC). São Paulo, Brazil (2010).

\begin{tabular}{|c|c|c|c|c|c|c|c|c|}
\hline \multirow{3}{*}{ NBC interventions } & \multicolumn{6}{|c|}{ Partogram areas } & \multirow{2}{*}{\multicolumn{2}{|c|}{$\begin{array}{c}\text { Total of women who underwent } \\
\text { the procedure }\end{array}$}} \\
\hline & \multicolumn{2}{|c|}{$\mathbf{I}$} & \multicolumn{2}{|c|}{ II } & \multicolumn{2}{|c|}{ III } & & \\
\hline & $\mathbf{N}$ & $\%$ & $\mathbf{N}$ & $\%$ & $\mathbf{N}$ & $\%$ & $\mathbf{N}$ & $\%^{*}$ \\
\hline Use of oxytocin & 13 & 100.0 & 0 & 0.0 & 0 & 0.0 & 13 & 56.5 \\
\hline Use of amniotomy & 13 & 92.9 & 1 & 7.1 & 0 & 0.0 & 14 & 60.9 \\
\hline Use of non-pharmacological methods & 17 & 100.0 & 0 & 0.0 & 0 & 0.0 & 17 & 73.9 \\
\hline Caesarian delivery indication & 14 & 60.9 & 6 & 26.1 & 3 & 13.0 & 23 & 100.0 \\
\hline
\end{tabular}

${ }^{*}$ Percentage in relation to the total of women of the sample $(n=23)$. 


\section{DISCUSSION}

In this study, the restricted amount of numbers was a limitation, primarily in regard to NBC data. This restriction may be responsible for the large dispersion of Odds Ratio in some results. However, it is important to emphasize that the data refer only to a one-year period and that, even so, does not invalidate this study.

In accordance with the WHO [11] and the Brazilian Ministry of Health recommendations [5], partogram registration must start at the beginning of the active phase of labor, that is to say, after more than $3-4 \mathrm{~cm}$ of cervix dilation, with 2 or 3 efficient uterine contractions every 10 minutes. When this occurs, in latent phase (period when, physiologically, cervix dilation and descent of fetal presentation slowly develop), lines of alert and action are easily surpassed and further interventions can be applied.

Unlike NBC that started partogram registration when every in-labor woman was in active phase of labor, TOC drew attention for having started $76.4 \%$ of the partograms during the latent phase of labor, although these women had been admitted and diagnosed as in the active phase of labor. This data is significant because an early start of partogram registrations predicts equally early interventions or, even, an elective caesarian delivery, due to a higher probability of an incorrect recognition of dystocia.

Obstetric interventions during latent phase of labor have undesirable effects. New interventions are frequently performed to ease or abolish such effects and, hence, a "splurge of interventions" is established, namely, a chain of events that include, among others, artificial rupture of membranes (amniotomy) and the use of hormones to accelerate delivery [12].

In case of low-risk pregnancies, the latent phase of labor must be conducted with expectation, guaranteeing vitality for mother and fetus. For monitoring labor, the phase or functional division of interest to apply the partogram is dilation, also referred to as the active phase during which the expected progression for cervix dilation is $1 \mathrm{~cm} /$ hour approximately. Accordingly, partogram registration in the latent phase or at the beginning of dilation (before $3-4 \mathrm{~cm}$ ) could lead to unnecessary and iatrogenic interventions [5].

Other possibilities of incorrect use of the partogram are: registration of data in a wrong column in relation to lines of alert and action and of evolution in intervals longer than 1 hour per column ${ }^{1}$. In analysis of records, there was statistical significance when both institutions

\footnotetext{
${ }^{1}$ In situations when cervix assessment is not performed in the subsequent hour, the partogram column remains blank. This means that vaginal examination can be performed in intervals longer than 1 hour however; the space for this hour in partogram must be preserved (each column of the instrument corresponds to 1 hour).
}

were compared $(p=0.000, \mathrm{OR}=42.2$ and $p=0.000$, OR $=53.3$, respectively), showing that the use of the partogram at NBC follows, more frequently, the filling-in of data as recommended by the Brazilian Ministry of Health.

Philpott and Castle [2] established that a line of alert in the partogram should be in the same line of the first register of cervix dilation, however in the following hour. After four hours, the line of action must be taken. Consequently, when the partogram has entries in the wrong column in relation to the lines, it can result in an incorrect identification and correction of a dystocia. On the other hand, as observed in Tables $\mathbf{2}$ and 3, the fact that, most interventions were performed in Area I of the partogram, reveals that, in both institutions, there was little influence of lines of alert and action regarding the intervention clinical decision.

In-labor women must undergo subsequent vaginal examinations every two hours in accordance with the Brazilian Ministry of Health [5], except in situations of intercurrences, considering the time expressed in chart for each registration. Cervix dilation, height of fetal presentation, positioning variety, and water-bag conditions are necessary to be evaluated and registered in the partogram for each one of the gynecologic examinations. The best result attributed to the NBC, in relation to registrations of labor progress (cervix dilation, descent of presentation, uterine contractions pattern, water-bag integrity) and fetal conditions (FHB and aspect of amniotic liquid) indicate that the model adopted in this Natural Birth Center respects the basic care recommendations regarding the use of the partogram.

Recent systematic review [13] compared NBC (named as "alternatives") with "conventional institutional settings for birth". They concluded that the alternative model does not present risk to mother or baby, is associated with reduced risk of medical interventions, has a higher probability of spontaneous vaginal delivery, has an increase in maternal satisfaction, and leads to a higher probability of breast-feeding after labor.

The registrations of usage of oxytocin are considered data of extreme relevance because of the imminence of risks in the indiscriminate use of this drug. This synthetic hormone was included in the list of the 11 high-alert medications of the Institute for Safe Medication Practices (ISMP) - a nonprofit organization that evaluates safety of medication available worldwide. This institute indicates that oxytocin result in further risks of damages when misused [14].

In accordance with the Brazilian Ministry of Health [5], the use of oxytocin must be registered in a partogram-instrument that favors the rational use of oxytocics, to wit, in the active phase or long pelvic periods. As a result, 5UI of hormone in $500 \mathrm{ml}$ of physiological se- 
rum or glucose serum at $5 \%$ is recommended at initial infusion of 4 drops/minute ( $2 \mu \mathrm{U} /$ minute), two-folding the dripping method every 30 minutes until the desired uterine contraction is obtained. It was observed in this study that, $58.4 \%$ of TOC women and $56.5 \%$ of NBC women underwent oxytocin use. However, TOC presented less concern in registering the infusion velocity, as well as the dosage of oxytocin infused. This event proves to be worrisome as the lack of registration does not endorse professionals of possible maternal-fetal intercurrences resultant of oxytocin infusion, and it likewise hinders the communication between teams in hospital shift changes, increasing maternal and fetal risks.

In another way, when Tables $\mathbf{2}$ and $\mathbf{3}$ are observed, both institutions presented initial infusion of oxytocin in Area I of the partogram. This means that in all cases the labor progress occurred apparently in accordance with normal expected patterns, which do not justify the possibility of trying to correct uterine contractions with oxytocin $^{2}$. Justifications for isolated professional conduct are to accelerate delivery and shorten mother suffering, although the use of oxytocin, for this end, increases the pain of contractions (women frequently complain about this effect) and it can contribute to a "splurge of interventions" [12,14]. Additionally, other studies [15] have shown that the use of oxytocin is associated with the way of birth. According to these authors, there is twice the risk of caesarian delivery when in-labor women undergo oxytocin use.

Non-pharmacological methods to relieve pain are on the WHO evidence list of useful practices to be stimulated during labor $[5,10]$. Several studies were performed to ratify the efficiency of such methods. In systematic review where 38 studies about the use of pain-relief techniques were included, among them, the bath, movement and massage concluded that they are safe, efficient and satisfactory for many women [16].

The bath momentarily reduces uterine contraction pains. In the first phase of labor, moving, remaining in vertical positions and freely changing positions can speed-up the active labor, as well as, women with low obstetric risk can have some comfort in the squatting position during the expulsion period [16,17]. Mamede [18] studied the deambulation effect on labor, verifying that the longer the walks at the beginning of active labor are, the shorter the labor period is.

TCO used non-pharmacological methods in only $19.1 \%$ of in-labor/pregnant women, and this data had no

\footnotetext{
${ }^{2}$ It is worth emphasizing that the population studied is compound of women who were diagnosed in labor; therefore it does not apply for women who received indication of oxytocin to induce labor (for example, post-term pregnancy with favorable conditions of the cervix). In this situation, such intervention should to be registered in the partogram from the beginning of the process respecting the track of lines of alert and action only when the active phase of labor is achieved (6).
}

statistical significance, demonstrating that the NBC care model has a higher potential to stimulate non-invasive methods to relieve pain and, consequently, promote delivery. The layout of a Natural Birth Center, with antepartum, labor and post-partum rooms, for example, encourages women to walk about the room or remain in the bath. Contrarily, professionals (obstetricians, obstetric nurses and doctors) are believed to be able to stimulate non-pharmacological methods to women even in small unfavorable spaces.

When also considering the use of the partogram with its tracked lines in hospitals, "there is no need of interventions when dilation is achieved or crosses the line of alert. Alert simply implies the necessity of a better clinical observation" ([5]: p. 48). Only in cases when the cervix dilation curve achieves the line of action, a medical intervention, not necessarily surgical, must be taken to improve the labor progression and/or correct possible dystocias that have been already started.

In the study of Rocha [9] performed in a natural birth center, obstetric interventions timely occurred, like in the case of amniotomy, for example, when a higher frequency occurred in the Areas II and III of the partogram. In this research, on the contrary, as described in Tables 2 and $\mathbf{3}$, there was a predominance of invasive interventions (oxytocin, amniotomy and caesarian section) in Area I of the partogram. For a population of low obstetric risk, hospitalized with an in-labor diagnosis, a higher number of registrations for intrapartum caesarian deliveries were expected in Area III of the partogram. This finding leads to questioning about obstetric practices in both institutions, regardless of the possible intercurrences occurred at the beginning of the labor registration.

\section{CONCLUSIONS}

As a conclusion of this study, the hospital with Natural Birth Center presented better results in regard to fillingin data the partogram, but did not present different results in comparison to the hospital with Traditional Obstetric Centers in relation to the moment of the interventions. Accordingly, regardless of the care model, the partogram is being used bureaucratically and not as a care guiding instrument aimed toward safe and opportune practices.

In populations considered low obstetric risk, these invasive interventions are expected to be more present in Areas II and III of the partogram (after line of alert). When they are present mainly in Area I of this instrument, even before using non-pharmacological methods, it is inferred that a rapid outcome of labor was sought and, as a consequence, often unnecessary or inappropriate technologies/interventions were used earlier than necessary.

This study questions safety, efficiency and efficacy of care practices, which are insufficiently guided in scien- 
tific evidence. It points out that, in traditional models of labor and birth care, as in Obstetric Centers, good practices recommended by the WHO and the Brazilian Ministry of Health must be incentivized. Diversely, even in models that had its physical structure idealized according to "humanized labor and birth" models, such as Natural Birth Centers, the presence of practices, not always based on better evidence are verified, suggesting that, more than the physical structure, human actions play an essential role in guaranteeing maternal and perinatal safety.

\section{REFERENCES}

[1] Groeschel, N. and Glover, P. (2001) The partograph. Used daily but rarely questioned. The Australian Journal of Midwifery, 14, 22-27.

http://www.sciencedirect.com/science/article/pii/S144543 $\underline{8601800215}$

http://dx.doi.org/10.1016/S1445-4386(01)80021-5

[2] Philpott, R.H. and Castle, W.M. (1972) Cervicographs in the management of labour in primigravidae. BJOG: An International Journal of Obstetrics \& Gynecology, 79, 599-602. http://dx.doi.org/10.1111/j.1471-0528.1972.tb14208.x

[3] Lavender, T., Tsekiri, E. and Baker L. (2008) Recording labour: A national survey of partogram use. British Journal of Midwifery, 16, 359-362.

[4] World Health Organization (1994) World Health Organization partograph in management of labour. Lancet, 343, 1399-1404.

[5] MS. Ministério da Saúde, Secretaria de Políticas de Saúde (2001) Parto, aborto e puerpério: Assistência humanizada à mulher. Brasília, Brazil.

http://dtr2001.saude.gov.br/editora/produtos/livros/popup /01_0420.htm

[6] Windrim, R., Seaward, G., Hodnett, E., Akoury, H., Kingdom, J., Salenieks, M.E., Fallah, S. and Ryan, G. (2007) A randomized controlled trial of a bedside partogram in the active management of primiparous labour. Journal of Obstetetrics and Gynaecology Canada, 29, 27-34.

http://www.sogc.org/jogc/abstracts/full/200701 obstetric s 3.pdf

[7] Lavender, T., Hart, A. and Smyth, R.M. (2009) Effect of partogram use on outcomes for women in spontaneous labour at term. Cochrane Database of Systematic Reviews. http://onlinelibrary.wiley.com/doi/10.1002/14651858.CD 005461.pub2/full

[8] Porto, A.M.F., Amorin, M.M.R. and Souza, A.S.R. (2010) Assistência ao primeiro período do trabalho de parto baseada em evidências: [Revisão]. Femina, 38, 527-537.
[9] Rocha, I.M.S., Oliveira, S.M.J.V. and Schneck, C.A. (2009) O partograma como instrumento de análise da assistência ao parto. Revista da Escola de Enfermagem da USP, 43, 880-888.

http://www.scielo.br/pdf/reeusp/v43n4/a20v43n4.pdf http://dx.doi.org/10.1590/S0080-62342009000400020

[10] Organização Mundial de Saúde (1996) Assistência ao Parto Normal: Um guia prático. Brasília, Brazil.

[11] World Health Organization (1994) Maternal health and safe motherhood programe. Preventing prolonged labour: A pratical guide. The Partograph Part I: principles and strategy. WHO, Geneva.

[12] Diniz, S.G. and Chacham, A.S. (2004) "The cut above" and "the cut below": The abuse of caesareans and episiotomy in São Paulo, Brazil. Reproductive Health Matters, 12, 100-110.

http://www.sciencedirect.com/science/article/pii/S096880 $\underline{8004231123}$ http://dx.doi.org/10.1016/S0968-8080(04)23112-3

[13] Hodnett, E.D., Downe, S., Walsh, D. and Weston, J. (2010) Alternative versus conventional institutional settings for birth. Cochrane Database of Systematic Reviews. http://www2.cochrane.org/reviews/en/ab000012.html

[14] Clark, S.L., Miller, D.D., Belfort, M.A., Dildy, G.A., Frye, D.K. and Meyers, J.A. (2009) Neonatal and maternal outcomes associated with elective term delivery. American Journal of Obstetrics and Gynecology, 200, 156.e1156.e4.

http://www.sciencedirect.com/science/article/pii/S000293 7808010375/pdfft?md5=0f153c9b756e6cdae3dfd7d75e2 9373b\&pid=1-s2.0-S0002937808010375-main.pdf

[15] Sakae, T.M., Freitas, P.F. and d'Orsi, E. (2009) Fatores associados a taxas de cesárea em hospital universitário. Revista de Saúde Pública, 43, 472-480.

http://www.scielo.br/scielo.php?script $=$ sci arttext\&pid $=\mathrm{S}$ 0034-89102009000300011\&lng=en http://dx.doi.org/10.1590/S0034-89102009000300011

[16] Simkin, P. and O'Hara, M.A. (2002). Nonpharmacologic relief of pain during labor: Systematic reviews of five methods. American Journal of Obstetetrics and Gynecology, 186, S131-S159.

http://www.sciencedirect.com/science/article/pii/S000293 $\underline{7802701889}$

[17] Enkin, M., Keirse, M.J.N.C., Neilson, J., Crowther, C., Duley, L., Hodnett, E. and Hofmeyr, J. (2005) Guia para atenção efetiva na gravidez e no parto. Guanabara Koogan, Rio de Janeiro, Brazil.

[18] Mamede, F.V. (2005) O efeito da deambulação na fase ativa do trabalho de parto. Ph.D. Thesis, Escola de Enfermagem of Universidade de São Paulo, São Paulo, Brazil. http://www.teses.usp.br/teses/disponiveis/22/22133/tde-2 2122005-105613/pt-br.php 